\title{
BONE AND STONE INDUSTRIES OF EARLY MAN IN CHINA
}

\section{SiNANTHROPUS}

$\mathrm{F}$ OR the first recognition of the fact that Sinanthropus had made and used implements of bone the archæological world is indebted to the Abbé Breuil. Before 1930, it was not known that the Choukoutien cave, in which the osteological remains of Peking man had been discovered, was an archæological site; but in that year Dr. Breuil recognized that the base of the antler from the cave, shown to him in Paris, had been burnt and fashioned into a tool by blows of a stone implement. Further discoveries of quartz flakes and burnt bones followed, and were in turn succeeded by the discovery of the rich cultural layer at the base of the Kotzetang in 1931. A visit to the site in that year by Dr. Breuil led to the identification of a large number of tools fashioned of bone or antler; and as these were not universally accepted without question, he was invited to make a further and more detailed study of them, of which the results are now made available*. It is to be noted that material found later than 1934 is not included in the report.

For the present purpose, the significant facts of the Choukoutien site may be summarized as follows : Locality 1, a completely collapsed cave filled with debris to a depth of 50 metres, shows five horizons each of which yields evidence of Sinanthropus. At the base of Level 4 is the famous cultural layer in Kotzetang. Three further sites only have yielded cultural remains of Sinanthropus age : Locality 13, older than Locality 1 , but only a few flakes and a single but fine chert artefact; Locality 15 , possibly connected with the eastern slope of Locality 1 and containing a remarkably rich and advanced lithic industry ; and Locality 4, still under excavation and yielding, at present, nothing but a few atypical broken stones.

No remains other than those of Sinanthropus occur from top to bottom of the deposits of Locality 1 , and there is, therefore, no valid reason for assuming the existence of another inhabitant of the cave, as do some prehistorians. Nor does the predominance of cranial remains support the suggestion of the practice of head-hunting, which belongs to a more advanced stage of culture, while in the only certain prehistoric example known (Ofnet, Bavaria) in all the specimens, as a rule young or feminine, the first two cervical vertebrae are retained and show marks of having been sectioned by a flint. At Choukoutien only one atlas, loose, has been found. The explanation here offered is that it is a deformation, an aberrant evolution from reverence for the family skulls as ensuring ancestral protection.

Certain criteria distinguish animal action on bones from that of man. The most likely to give rise to uncertainty are the hyæna, the beaver and the porcupine. The crushing action of hyæna jaws is difficult to distinguish in effect from the hammeranvil blow of man, though a hyæna never splits a bone lengthwise. A single bite by a beaver or porcupine may make a double or single incision which resembles a notch made by a metal tool, while their action in gnawing the end of a bone may look like

* Bone and Antler Industry of the Choukoutien Sinanthropus Site By Henri Breuil. Translated by Miss M. E. Boyle. Paloeontologia Sinica, N.S.D., No. 6, Peking, 1939 , pp. $40+26$ plates. a point chopped by man. This is the origin of the so-called 'worked' elephant bones of Piltdown.

From the point of view of the toolmaker, three stages in fossilization are to be distinguished: (a) when still fresh the bone breaks cleanly and can be used readily for implements; $(b)$ in the first stage of fossilization disintegration predominates over mineralization, bone is brittle, tends to crumble and has an irregular fracture ; $(c)$ complete fossilization renders it capable of being broken cleanly and sharply, but the outside and inside being usually of a different colour, breaks can easily be seen. The bones found at Choukoutien all belong to Stage $(a)$.

In considering the industries of the earlier palæolithic periods, while it is admitted that, in addition to stone, man must have used wood, which has perished, it is usually overlooked that in bone man had at hand a convenient and adaptable material most of which also must have disappeared. The bone industry was first developed but was not invented. in Upper Palæolithic times.

From the days of Sinanthropus, man has used horns of antelope, gazelle, goat and young ibex (ox horns being too big) antlers and stag-horns, skulls, jaw-bones, long bones, whole or broken, fragments of diaphyses, and flakes, short bones, chiefly astragals, carpus, tarsals and phalanges, vertebrae, ribs, iliac bones and shoulder blades, which in the Upper Palæolithic show evidence of having been used as shovels or scrapers.

Thus bone was used whenever a hard substance was needed, exactly like any stone, from the dawn of human toolmaking. The facts at Choukoutien confirm exactly observations at Castillo, Santander, Spain, as against the contention that the palæolithic bone industry is confined to the Upper Palæolithic and some rare Mousterian objects.

The material used at Choukoutien and identified includes horns and skulls of deer and ruminants, jaw. bones and teeth of deer, wild boar, fragments of elephant ivory, maxillæ of Carnivora (hyæna, leopard, tiger, bear), body and leg bones, including shoulder blades, humerus, radius, femur and tibia of deer, horse, rhinoceros, hyæna, bear, etc. The anatomical origin of a large number of flakes is difficult to determine.

An interesting and important point to emerge is that the state of the deer antlers points to a seasonal migration among them. All except two of the antlers of Pseudaxis are attached to the skulls and must have been so born when the animal was killed, while in Euryceros the majority of antlers have been shed. The antlers being shed at the beginning of winter after the rutting season, evidently the Euryceros migrated from the highlands to avoid the cold and occupied the country of the Pseudaxis, which retired before them until they retreated in the following year. The absence of halfgrown antlers suggests that during the five months until the end of summer, Sinanthropus either left his cave or did not eat animals.

\section{The Upper Cave}

The Upper Cave at Choukoutien, when discovered in 1930 during the search for Sinanthropus remains, was considered of relatively little importance; but 
when it was fully excavated in $1933-34$, it was found to be of unique character in Chinese prehistory. In it were found not only artefacts of an Upper Palæolithic culture, but also the skeletal remains of a number of individuals representative of Upper Palsolithic man in China, who hitherto had been unknown. The results of the excavation of the cave are to be described in a series of monographs, of which that dealing with the archæology by W. C. Pei is the first to appear*.

The Upper Cave, previous to excavation, was completely covered by the superficial soil of the hill and filled with deposits, consisting of a grey loam mixed with fragments of collapsed rock. This was completely removed down to the red and hard breccia of the Choukoutien formation, in which further excavation would have been unprofitable. The cave consists of an upper room, a lower room and a lower recess, a narrow cavity three metres long and one metre wide, forming the lowest part of the cave. Five cultural layers were distinguished. It is possible that the Lower Room, in which human remains, including three complete skulls, were found, may have been a burial place only and not a dwelling site. In the lower recess an accumulation of animal bones and skeletons alone was found.

* The Upper Cave Industry of Choukoutien. By Pei Wen Chung. Palcontologica Sinica, N.S.D., No. 9, 1939, pp. $41+8$ plates.
Occupation lasted up to the complete filling of the upper room. The Upper Cave industry is characterized by a poorly developed, or at least poorly represented, lithic industry in which chert, sandstone, quartz, all foreign to the site but found in the vicinity, are in use. The types of implements include scrapers, choppers, as well as pebble implements. A notable feature is the use of personal ornament-perforated pebbles, stone beads with large perforation and one ground surface. The bone, antler and shell industries, mostly reserved for ornamental purposes, are most characteristic, and being usually left in natural shape are typical of a 'primitive' industry. A remarkable find is a bone needle, such as was not known hitherto to have occurred in China before Neolithic times. The technique of polishing is to be observed on a deer antler and the jaw-bone of a Sika deer.

As a whole, the Upper Cave industry is clearly ranged within an Upper Palæolithic stage, but on comparison with its European equivalents it shows a mixture of relatively primitive and relatively advanced characters. It is likely that these artefacts represent an isolated culture of their own, indebted in part to a northern 'palæarctic' culture, in part to a Pacific culture sheet extending from Malaya to Manchukuo. It may on palæontological and archæological grounds be regarded on the Eastern equivalent of the Western Late Magdalenian.

\section{FOOD PRODUCTION WITHOUT ARTIFICIAL FERTILIZERS}

\section{By YSABEL DALDY}

\begin{abstract}
$\mathrm{A}^{\mathrm{s}}$ N ACCOUNT of a valuable experiment in the feeding of schoolboys on vegetables and fruit grown from soil manured exclusively by humus is published by Dr. G. B. Chapman, of the Physical and Mental Welfare Society of New Zealand, Incorporated (Burnock Publications, Auckland, 1939). The locale of the experiment is the Mount Albert Grammar School hostel, the subjects being some sixty boys, teachers and staff. At the time of the inception of the experiment (1936), the dietary at the hostel was liberal, being well above the customary standard for boarding-schools; yet the boys consistently suffered (as was the case in other New Zealand schools and institutions) from colds, catarrh, septic tonsils, epidemics of influenza, dental caries and other preventable complaints. The whole of New Zealand's food supplies are grown from soils manured by the ordinary chemical fertilizers.
\end{abstract}

Dr. Chapman opened his campaign in 1936 by delivering a few short lectures to the resident teachers and boys, advising the growing of the hostel's fruit and vegetables from soils to be treated by properly prepared humus. He was successful in arousing the interest of the teachers, the boys, the matron and the staff. The reform was put in hand and the change-over made from 'chemically grown' fruit, salads and vegetables to the 'naturally produced' foods now in use at the hostel. At the present time, approximately an acre of land is under cultivation for the benefit of the hostel, to the soil (black volcanic) of which no chemical or artificial fertilizers of any kind have been applied. The area in question is supplying the greater proportion of the green vegetables, salad-greens, pumpkins, kumaras, rootvegetables and fruit required by a household of some seventy-seven persons. The following general report of progress in health since the time of the changeover has been submitted by the matron of the hostel (pp. 4-6, "Menus and Recipes", Chapman and Lowe, 1939) :

"The first thing to be noted, during the twelve months following the change-over to garden produce grown from our humus-treated soil, was the declining catarrhal condition among the boys. Catarrh had previously been general and, in some cases, very bad among the boys. In specific cases the elimination was very marked and in many cases complete. There was also a very marked decline in colds and influenza. Colds are now rare and any cases of influenza very mild. Coming to the 1938 measles epidemic, which was universal in New Zealand, the new boys suffered the more acute form of attack; while the boys who had been at the hostel for a year or more sustained the milder attacks, with a much more rapid convalescence.

"During the past three years there has been a marked physical growth and development during terms of heavy school work and sport [actual heights and weights are quoted]. In some cases boys go through a period of indisposition for several weeks after entering the hostel. This would appear to indicate that the method of feeding causes a certain detoxication period which, when cleared up, does not return. Excellent health gradually ensues in all cases, and is maintained. There are fewer accidents, particularly in the football season, which would possibly indicate that the foods in use contain the optimum amount of minerals and vitamins, thus ensuring a full development of bone and muscle and a greater resiliency to fractures and sprains. The 